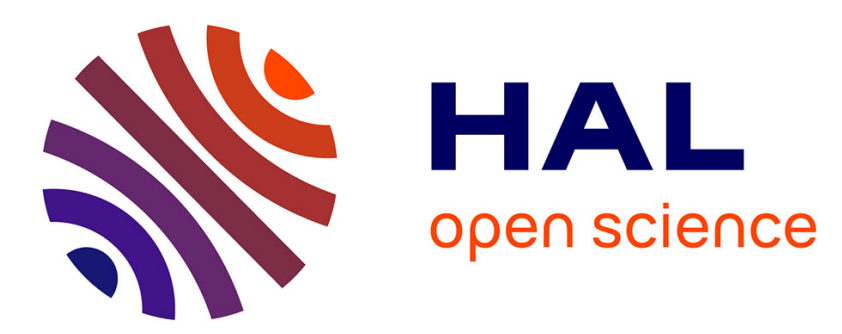

\title{
A. STRUCTURE INFORMATIONAMORPHOUS SOLID FORMATION AND INTERSTITIAL SOLUTION BEHAVIOR IN METALLIC ALLOY SYSTEMS
}

D. Turnbull

\section{To cite this version:}

D. Turnbull. A. STRUCTURE INFORMATIONAMORPHOUS SOLID FORMATION AND INTERSTITIAL SOLUTION BEHAVIOR IN METALLIC ALLOY SYSTEMS. Journal de Physique Colloques, 1974, 35 (C4), pp.C4-1-C4-10. 10.1051/jphyscol:1974401 . jpa-00215592

HAL Id: jpa-00215592 https://hal.science/jpa-00215592

Submitted on 1 Jan 1974

HAL is a multi-disciplinary open access archive for the deposit and dissemination of scientific research documents, whether they are published or not. The documents may come from teaching and research institutions in France or abroad, or from public or private research centers.
L'archive ouverte pluridisciplinaire HAL, est destinée au dépôt et à la diffusion de documents scientifiques de niveau recherche, publiés ou non, émanant des établissements d'enseignement et de recherche français ou étrangers, des laboratoires publics ou privés. 


\title{
AMORPHOUS SOLID FORMATION AND INTERSTITIAL SOLUTION BEHAVIOR IN METALLIC ALLOY SYSTEMS
}

\author{
D. TURNBULL \\ Division of Engineering and Applied Physics \\ Harvard University \\ Cambridge, Massachusetts 02138, USA
}

\begin{abstract}
Résumé. - Les modèles pour la transition état fondu $\leftrightarrow$ solide amorphe et pour la structure des solides amorphes dans les systèmes métalliques seront rappelés. L'expérience suggère que la tendance à former des verres métalliques est plus grande dans les systèmes composés principalement de métaux nobles ou de certains métaux de transition (A) auxquels sont mélangées de plus faibles quantités de certains métalloïdes ou d'éléments électropositifs (B). Souvent la formation des phases liquides de ces alliages $\mathrm{AB}$ est accompagnée de transfert de chaleur, d'un excès d'entropie de mélange ou d'une contraction en volume. Les effets de la composition sur la tendance à former des alliages vitreux seront discutés en tenant compte de ces résultats et dans le cadre des modèles structurels auxquels on se réfère.

Nous remarquons aussi que la diffusion ultra-rapide d'impuretés a lieu dans les alliages où un élément du type B est la matrice cristalline et un élément du type A est l'impureté. L'expérience montre très clairement que ce transport rapide est effectué de façon prédominante par des défauts de type interstitiel, qui, contrairement aux règles empiriques du rapport des dimensions des atomes donnant le comportement des solutions, doivent être constitués par de substantielles proportions du composant A. Les récentes études de frottement intérieur de Turner et de ses collaborateurs suggèrent que dans les systèmes plomb-métal noble les défauts ont des configurations interstitielles excentrées. Nous suggérons que ce comportement interstitiel des solutions puisse provenir du même type d'interactions $A-B$ qui sont responsables de la forte tendance à former des verres dans les alliages où $\mathrm{A}$ est la matrice. Ces interactions seront discutées à la lumière des corrélations habituelles relatives à la formation des alliages.
\end{abstract}

\begin{abstract}
Models for the melt $\leftrightarrow$ amorphous solid transition and for the structure of amorphous solids in metallic systems will be reviewed. Experience suggests that the tendency toward formation of metallic glasses is greatest in systems composed mainly of noble or certain transition metals (A) admixed with smaller amounts of certain metalloidal or electropositive elements (B). Often the formation of the liquid states of these AB alloys is accompanied by heat evolution, excess entropy of mixing or some volume contraction. The effects of composition on alloy glass forming tendency will be discussed in view of these data and in terms of the structural models alluded to.

We note also that the occurrence of ultra-fast impurity diffusion is in alloys where a B type element is the crystalline host and an A type element is the impurity. Experience shows quite conclusively that this rapid transport is effected primarily by interstitial type defects, which must, contrary to the empirical atom size ratio rules for solution behavior, be constituted by substantial proportions of the A component. The recent internal friction studies of Turner and associates suggest that in the lead-noble metal systems the defects have off-center interstitial configurations. We suggest that this interstitial solution behavior may stem from the same type of A-B interactions which are responsible for the strong glass forming tendency in alloys where $\mathrm{A}$ is the host. These interactions will be discussed in view of current correlations of alloying behavior.
\end{abstract}

Introduction. - Alloys formed by composing (A), noble and some transition (those with nearly full $\underline{d}$ shells) metals, with (B), the more electropositive elements, frequently exhibit unusual glass forming and diffusion behavior. In particular, alloys in which A is the major constituent exhibit strong glass forming tendencies while metals of the B group often are hosts for ultra-fast diffusion of $\mathrm{A}$ impurities. These rather different types of behavior actually may stem from similar A-B interactions. In this paper metallic glass formation and ultra-fast diffusion will be surveyed with particular emphasis on their interrelation and the problems which the A-B interactions seem to pose for alloy theory. We begin by reviewing the models for the structure and formation of amorphous metallic solids.

\section{Formation and structure of amorphous metallic} solids. - 1.1 PURE MONATOMIC SYSTEMS. - It is well known that the specific volume, specific energy and short range atomic order (SRO), as defined by the number and spacing of nearest-neighbors in a WignerSeitz construction, of most metals change rather little in the crystal $\leftrightarrow$ melt transition. These transition characteristics naturally gave rise to the view that the structure of liquid metals should be modelled satisfactorily by that of a defective crystal, such as a dynamic microcrystalline assembly. However later 
developments $[1 \mathrm{~A}]$, led to quite a different view of the nature of the SRO in amorphous metals, molten or solid. In particular, there were the demonstrations $[1,2,3]$ that large undercoolings, at least 0.2 to 0.33 of the thermodynamic crystallization temperature, $T_{\mathrm{m}}$, are required to nucleate crystallization in finite systems of clean molten metals. Further, the model studies of Bernal and others [4] showed that assemblies of uniform hard spheres formed by 3-dimensional random packing collapse upon compression, not to a crystalline state but to a dense random packed (DRP) structure of a high density containing a prominent admixture of non-crystallographic configurations. Owing to these configurations, which in their idealized forms often exhibit pentagonal symmetry, the crystallization of the DRP structure can occur only by a reconstructive process. In the mean field, or free volume model for the liquid $\leftrightarrow$ glass transition, developed by Cohen and the author [5], the DRP structure models the «ideal» monatomic glass toward which the amorphous system would relax when crystallization does not intervene [6].

In view of this model, it is instructive to consider the results of computer studies on the dynamics of transport and solidification in 3-dimensional systems of uniform hard spheres, where the mean field model should precisely apply. These studies [7] have established that thermodynamic crystallization in hard spheres begins at a fluid density $v_{0} / v \sim 0.67$ relative to that, $1 / v_{0}$, of the ideally close packed crystal. This density is far less than that, $\sim 0.86$, of the DRP structure which is therefore metastable relative to the crystal. Further [8], see figure 1, the self-diffusivity, $D$, is falling precipitously and the shear viscosity, $\eta$, is climbing steeply with increasing fluid density at the crystallization point. From this behavior, as well as the free volume extrapolation of it $[5 \mathrm{c}]$, it seems apparent that $D$ and $1 / \eta$ would have virtually vanished well before the DRP density is reached. Actually, Bennett [9] reports molecular dynamics computations indicating $D \sim 0$ in a system in the DRP configuration, in which Lennard-Jones interatomic potentials operate, compressed until the total potential energy is zero. These results support the hypothesis of Cohen and the author [6] that the DRP structure models an ideal monatomic glass in internal equilibrium and that, except for the intervention of crystallization, the hard sphere fluid would, in supercompression, solidify continuously toward the glass state. We note that the essential difference between the fluid and solid states is in the nature of the molecular motions. In the fluid these motions are, in large part, translatory, or diffusive, corresponding to a correlation factor, $f$, not far less than unity, while in the solid, whether amorphous or crystalline, $f \sim 0$, i. e., the motions are almost wholly oscillatory.

It might appear that the preparation and retention of the DRP structure, since it is much less stable than the crystal, would be quite difficult. Actually a non-

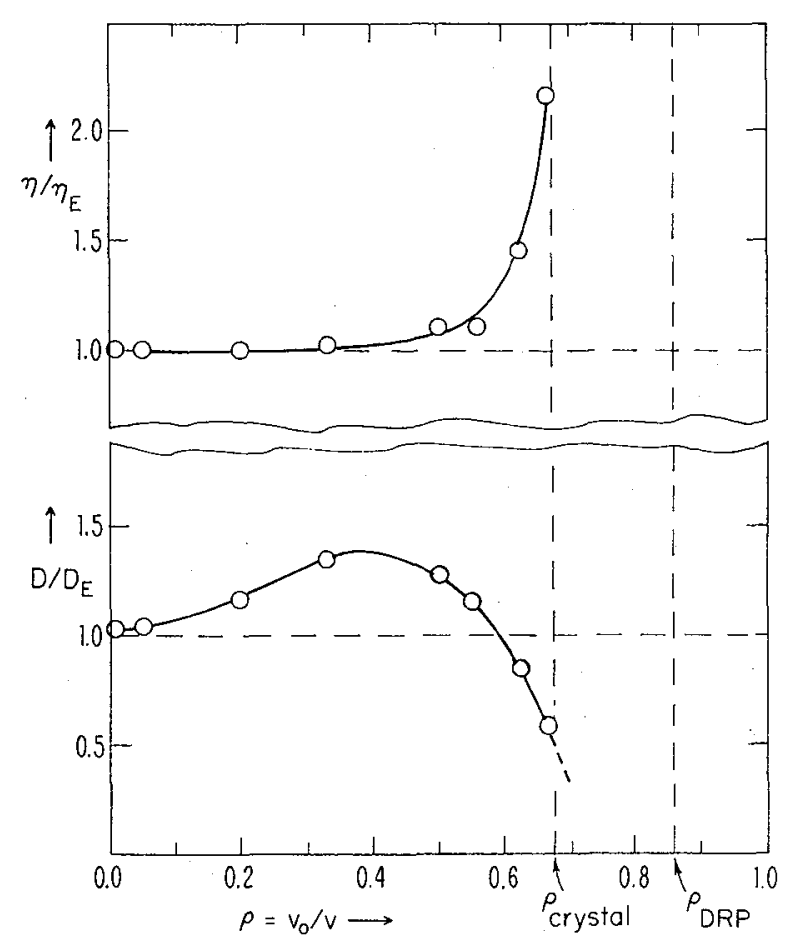

FIG. 1. - Summary of Alder et al's [8] results on dependence of self-diffusivity, $D$, and shear viscosity, $\eta$, of 3-dimensional hard sphere fluid on density, $\rho, \mathrm{E}$ denotes Enskog.

ideal DRP structure appears quite readily in small model systems [10] by processes which are probably akin to vapor quenching. Also a similar structure sometimes appears upon supercompression of the fluid state of small dynamic systems [6].

What guidance the results on hard sphere systems offer in the interpretation of structure and transport behavior of actual monatomic, especially metal, systems will now be considered. First, we note, see Table I, that at the crystallization points, the densities of monatomic fluids, relative to the corresponding crystals at $0 \mathrm{~K}$, are well above the density of the hard sphere fluid. Within the framework of the mean field model these results reflect the relative softness of repulsive forces in atomic systems. To compare the atomic with the hard sphere results it is customary to define a temperature dependent atomic "hard core " diameter in terms of an interatomic pair potential ; e. g., this diameter might be defined as the interatomic separation at the point on the repulsive branch of the potential which is $k T$ above the minimum. In this way Alder and Dymond [11] showed that the transport behavior in fluid argon is entirely consistent with the predictions of the mean field model (MFM). Recently a similarly modified MFM has been used to interpret the heat capacity [12] and atomic transport $[13,14]$ behavior of liquid metals.

It seems likely that in an amorphous system the nature of the SRO will be dictated largely by short range interatomic interactions. Frank [15] pointed out some time ago that the SRO most favored by these 


\section{TABLE I}

Ratio of specific volume of amorphous state to that of crystal at $0 \mathrm{~K} . T_{\mathrm{m}}$ designates thermodynamic crystallization temperature. Estimates made from results summarized by Borelius, G. Sol. Stat. Phys. 15, (1963) 1 [ed. Seitz and Turnbull], Academic Press, N. Y.

$\begin{array}{cl}\text { System } & v_{\mathrm{a}} / v_{\mathrm{c}}^{0} \\ \text { Hard Spheres } & - \\ \text { Fluid at Cryst. Point } & 1.49 \\ \text { DRP Structure } & 1.165 \\ \text { Liquids at } T_{\mathrm{m}} & \\ \mathrm{A} & 1.25 \\ \mathrm{Na} & 1.09 \\ \mathrm{~Pb} & 1.085 \\ \mathrm{Cu} & 1.125 \\ \mathrm{Ag} & 1.12 \\ \mathrm{Au} & 1.125 \\ \mathrm{Ni} & 1.135\end{array}$

interactions is not necessarily of the type which could, by itself, serve as a crystal building unit. Recent model studies have supported this concept and illuminated it further. Thus Bennett [16] notes that in the 3-dimensional serial deposition of hard spheres the operation of short range potentials alone, strongly favors the formation of groupings in which the centers of 4 mutually contacting spheres delineate a regular tetrahedron. A close-packed crystal structure must contain one octahedral group for every two tetrahedral groups. However, Bennett points out that by itself an octahedral group of six spheres can decrease its volume by collapsing to a configuration consisting of 3 tetrahedra sharing a common edge. For this reason the occurrence of octahedral configurations in systems, whether solid or molten, where the behavior is dictated by very short range forces should be rare and model studies seem to confirm this expectation. It is this difficulty of forming octahedral groups which provides the microscopic basis for explaining why molten metals exhibit high resistance to homogeneous crystal nucleation and may have some potential for glass formation.

Since space cannot be filled by the packing of regular tetrahedra alone, the problem arises: How might a macroscopic body accommodate its configurations to short range forces favoring tetrahedral groupings other than by crystallization ? Polk [17] noted that the Bernal DRP structure might be thought to be composed by the assembly of a high density of tetrahedral configurations with admixture of a small concentration of larger holes to achieve space filling. The idealized forms of these larger holes had been specified already by Bernal. Viewed in this way the tetrahedral void fraction, which is $2 / 3$ in close packed crystals, is 0.86 in the DRP structure. Presumably, it is the presence of the larger voids which is responsible for the lower density and higher potential energy of the DRP relative to the close packed crystal structure. It may be that the more loosely packed random structures are similar to the DRP excepting for higher proportions of the larger holes. This possibility merits further exploration.

The foregoing considerations suggest that isolated clusters of atoms, interacting by centrosymmetric potentials would, when sufficiently small, be more stable in a non-crystalline than in any crystalline configuration; and the question arises: What size must the cluster reach in order for its most stable configuration to be crystalline ? An early calculation by Frank [15] indicated that a 13 atom cluster should be most stable when a central atom is surrounded icosahedrally by 12 neighbors. In this configuration the outer atoms, considered as hard spheres, would not be in contact. Consequently, with some softening of the repulsive potential, it would relax to a state of lower potential energy than could the two crystallographic configurations in which the outer atoms are in contact prior to the relaxation. Recently there have been several calculations of the number and energy densities of larger atom clusters [18, 19]. In one of these [19c] Hoare and Pal showed that with a LennardJones interatomic potential clusters containing up to at least 66 atoms are more stable in some non-crystallographic than in any crystalline configuration. These results lend further support to the idea that initiation of crystallization in a 3-dimensional atomic system would require substantial reconstruction of the SRO.

Bennett [16] notes that in 2-dimensional systems the short range interactions will most favor the formation of triangular groupings of particles. Since these can be assembled to fill space, it is possible that a 2-dimensional system of random packed discs would, in contrast with the 3-dimensional system, collapse to a crystalline arrangement upon compression. There is the corollary implication that the 2-dimensional amorphous systems, e. g., smectic layers of ordered fluids, may exhibit much less resistance than do 3-dimensional systems to homogeneous crystal nucleation.

In an actual atomic system the differences of both the specific energy and volume between the infinite DRP and crystalline structures should be reduced substantially with softening of the interatomic repulsive potential. This effect was demonstrated by the calculations of Weaire et al. [20] on pure metals in which a fitted Morse interatomic potential was used. A further interesting outcome of these calculations was the finding, in agreement with the Bennett result, that with the assumed potentials the DRP structure is actually in metastable internal equilibrium, i. e., it is stable against infinitesimal distortions.

The foregoing considerations are the microscopic basis for the concept of Cohen and the author $[5,6]$ 
that, if crystallization could be bypassed, all monatomic fluids would exhibit a liquid $\leftrightarrow$ glass transition ; i. e., solidify continuously with falling temperature to solids with DRP like structures. Actually in pure metals cooled at normal rates, crystallization apparently always intervenes before the glass temperature, $T_{\mathrm{g}}$, is reached; i. e., $T_{\mathrm{g}}$ lies below 0.65 to $0.8 T_{\mathrm{m}}$. It should be possible to put these metals into amorphous solid form by deposition - vapor, electro or ion sputtering — onto sufficiently cooled, (i. e., well below $T_{\mathrm{g}}$ ) substrates. Amorphous films so formed should withstand heating to $T_{\mathrm{g}}$ without crystallization provided there are no crystallization centers on the substrate. However, it has been noted [12, 21, 22] that the normal scaling relation between crystal growth rate, $u$, and reciprocal viscosity, $1 / \eta$, may not apply to a high purity monatomic system. More particularly, $u$ may scale as the Enskog diffusivity, $D_{\mathrm{E}}$, rather than as the actual $D$ since the atomic motions required for growth of the crystal apparently are not as restricted by interparticle interferences as those required for atomic transport within the amorphous phase. It follows that high purity amorphous films may crystallize well below $T_{\mathrm{g}}$ by growth from crystallization centers in the substrate. It seems plausible that the mobility of large angle grain boundaries in high purity material should mark the lower limit of that of the crystal - amorphous solid interface.

In amorphous films of lesser purity some reordering or redistribution of impurity may be required in order for crystal growth to proceed. Such impurity motions should occur by mechanisms akin to those in atomic transport or flow and the attendant crystal growth rate may therefore scale as $1 / \eta$. In this event, the kinetic crystallization temperature range may mark $T_{\mathrm{g}}$, approximately.

Recently there have been reports of success in depositing films of pure metals in amorphous solid forms but the composition and structures of these films seem not to be fully characterized yet. Bennett and Wright [23] have reviewed some of these results and report on their own preparations of amorphous films of some of the transition metals. They observed that the kinetic crystallization temperatures of their films were increased sharply by the presence of relatively small amounts of impurities. Davies et al. [24] report that very small and thin $(\sim 0.1$ micron) sections at the edges of a splat quenched $\mathrm{Ni}$ foil were amorphous at room temperature. Since the quench rate was extremely high, $\sim 10^{10} \mathrm{~K} / \mathrm{s}$, this behavior seems compatible with the expected crystal nucleation rate of molten Ni. However, in view of Bennett and Wright's results, it seems surprising that the amorphous $\mathrm{Ni}$, if pure, was not transformed by outward growth of crystalline $\mathrm{Ni}$ from the more massive parts of the foil.

Actually, Hilsch et al. [25] had shown some time ago that in vapor deposition both the formation tendency and kinetic stability of amorphous metallic solids are sharply enhanced by admixture of certain impurities, and these effects were essentially confirmed by Nowick and Mader [26, 27]. The first successes of Duwez and associates [28] in melt quenching to amorphous metallic forms apparently were facilitated greatly by the alloying additions. Since these experiments, the variety of alloys put into amorphous solid form has been extended greatly. Further, the occurrence of the liquid $\leftrightarrow$ glass transition in some of the alloys was demonstrated by both thermal and rheological measurements $[29,30]$. Recently, these and other results on the formation, structure and properties, of amorphous solid alloys were reviewed fully and critically by Giessen and Wagner [31]. In the following, some aspects of alloying effects on metallic glass formation are discussed in terms of the DRP type of structural models.

\subsection{The ROLE OF ALloying IN METALliC Glass} FORMATION. - In general, impurity additions may facilitate glass formation in the following ways : $[12,31,32]$ (1) by increasing the stability of the amorphous state, molten and solid, relative to the crystal at the same composition; (2) by increasing the temperature of the liquid $\leftrightarrow$ glass transition or, as we have noted already, (3) by decreasing, apart from the driving free energy factor, the rate of crystal growth. This effect would be pronounced if some local compositional reordering were required for crystal growth.

We note (see Giessen-Wagner [31] review of amorphous alloy compositions) that the alloys which have been put into amorphous solid forms are composed primarily by (A) noble or transition metals having filled or nearly filled $\mathrm{d}$ bands with some admixture, usually, of (B) metalloidal elements or others, including early transition metals, which appear to be nearly free electron like in their metallic state behavior. All amorphous alloys so far formed by melt quenching have contained both A and B components, but Nowick, Mader et al. [26] have vapor deposited some, e. g., $\mathrm{Cu}-\mathrm{Ag}$ and $\mathrm{Au}-\mathrm{Co}$, consisting of $\mathrm{A}$ elements only. In most such alloys, the major constituent is an $\mathrm{A}$ element but in some, e. g., vapor deposited $\mathrm{Cu}-\mathrm{Sn}$ and melt quenched $\mathrm{Cu}-\mathrm{Zr}$, the $\mathrm{B}$ compositions have exceeded 50 at $\%$. Of course there is no assurance that the structures, which have been thoroughly characterized for only a few systems, of all the amorphous alloys are essentially similar [30a, 31].

It appears [32] that the metals most likely to exhibit the highest glass temperatures would be those in which the interatomic repulsive potentials are climbing most steeply with decreasing neighbor-neighbor separation. It is difficult to evaluate precisely the interatomic pair potentials for metal hosts. However, it has long been thought $[33,34]$ that in metals of the $A$ type the core-core repulsive interactions probably increase sharply with decreasing interatomic separations near the Wigner-Seitz f. c. c. separation. Thus, it is in these metals that hard sphere repulsive 
behavior may be most nearly simulated and this may be reflected by their relatively high Grüneisen constants, as was pointed out by Mott and Jones [33], as well as by their relatively large volume expansions (see Table I) between the crystal at $0 \mathrm{~K}$ and the liquid at $T_{\mathrm{m}}$. From this point of view it is not surprising that A type metals are highly favored as hosts for alloys which form amorphous solids. We have no direct information on the glass temperatures of pure $A$ metals. Often the temperature of crystallization on heating, $T_{\mathbf{c}}$, marks the approximate glass temperature. If so, $T_{\mathrm{g}}$ of one amorphous mixture of A metals, $\mathrm{Cu}_{50} \mathrm{Ag}_{50}$, formed by vapor quenching would be $\sim 370 \mathrm{~K}$.

Nowick and Mader [27] attributed the favorable effect of alloying on amorphous solid formation primarily to differences between the atomic sizes, as specified by the Wigner-Seitz volumes of the alloy constituents. It appeared that this size non-uniformity would greatly slow the rate of crystal growth and thereby kinetically stabilize the amorphous structure. Apart from this kinetic effect, atomic size dispersion may sometimes increase the relative thermodynamic stability of the amorphous state. More particularly, it is plausible that the filling of space by the random packing of hard spheres may be more complete with spheres having certain size distributions than with spheres of a single size $[35,36]$. Experience seems to support this expectation. For example, Ashby [37] observed that densities within about $2 \%$ of that of crystalline close packing of uniform spheres are reached in the random packing of two sets of spheres with the diameter ratio $1.2 / 1.0$. With normal interatomic potentials this higher packing density should lead to relative lowering of the potential energy of the amorphous state in actual atomic systems. The RDFs of model systems composed by the dense random packing of two sets of hard spheres with different diameters have been investigated by Polk [38] and by Dixmier et al. [39].

While the foregoing interpretation of alloying effects is highly plausible, there are some amorphous alloys in which the size differences, as defined, are quite small. An example (see Figure 2) is the amorphous $\mathrm{Ni}-\mathrm{P}$ system $\left(\mathrm{Ni}_{3} \mathrm{P}\right.$ to $\left.\mathrm{Ni}{ }_{7} \mathrm{P}\right)$ in which the atomic volumes of the constituents apparently differ by no more than 1-2\% in either the crystalline or the amorphous states [35]. In this system, as well as in the A-B amorphous alloys formed by melt quenching, it appears that relative stabilization of the amorphous state by the $\mathrm{B}$ additions may have had a decisive role in facilitating the glass formation.

Indeed, all of these A-B type glass forming systems exhibit, either in their molten or some intermetallic compound state, negative heats of mixing when formed from the corresponding states of their pure constituents. The thermal measurements of Chen and the author $[29,30]$ indicate that a high degree of local compositional order develops in molten $\mathrm{Au}_{4} \mathrm{Si}$ and $\mathrm{Pd}_{4} \mathrm{Si}$

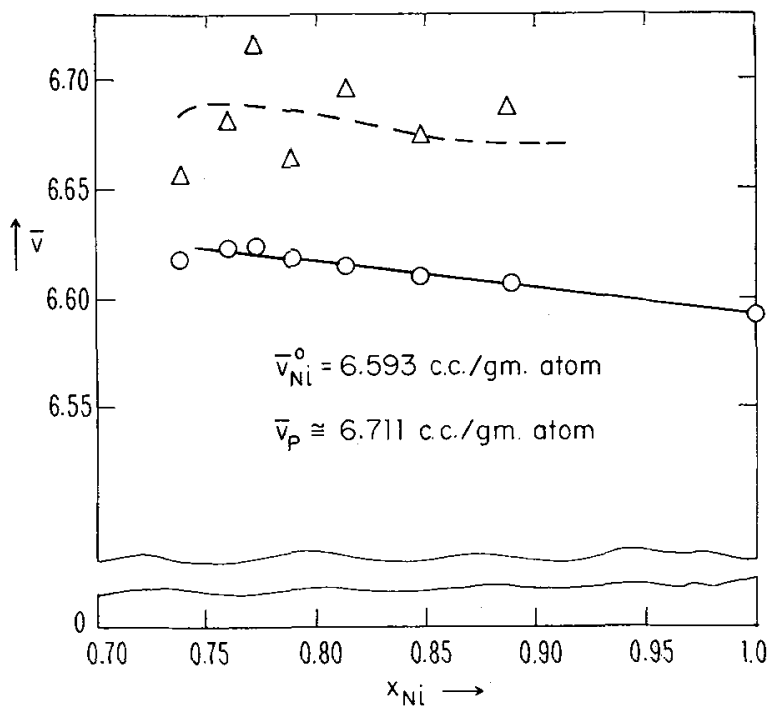

Fig. 2. - Summary of Cargill's [35] measurements $(T=300 \mathrm{~K})$ of dependence of gram-atomic volume of $\mathrm{Ni}-\mathrm{P}$ alloys on atom fraction, $x_{\mathrm{Ni}}$, of $\mathrm{Ni}$. $\odot$ denotes equilibrium crystalline mixture,

$\mathrm{Ni}+\mathrm{Ni}_{3} \mathrm{P}$, and $\Delta$ denotes homogeneous amorphous solid.

based alloys as they are cooled toward their glass transition temperatures. The systems which seem most prone to glass formation in melt quenching are those having compositions lying at and near to abnormally low-lying eutectics. These abnormal eutectics would seem to reflect that the alloys are exceptionally stable in their amorphous states.

Figure 3 shows the phase diagram for one such system, Au-Si, compared with the diagram calculated by applying the ideal solution model to the major constituent of the liquid phase. We note that the liquidus courses follow those calculated fairly well in the relatively dilute solution ranges but then dip sharply to a eutectic temperature of $\sim 640 \mathrm{~K}$ which is far below the calculated $\sim 1145 \mathrm{~K}$. Cohen and the writer [40] pointed out that this relative stabilization of the amorphous state ought to lessen the gap between $T_{\mathrm{m}}$ and the glass temperature and thus facilitate bypassing of crystallization in the melt quench.

Cargill [36] demonstrated that the DRP structure, as characterized by Finney [41], gave the best fit, of the models tested, to the RDFs of a number of amorphous alloys in which a single A element is the predominant constituent. Later Polk [17] showed that the relative stability and atomic density of the DRP structure may be increased markedly by the placement of impurity atoms in the larger of the structural voids already alluded to. In its idealized form the atomic environment of the largest of the voids is quite like that of the metalloid atoms in the intermetallic $A_{3} B$ (e. g., $\mathrm{Pd}_{3} \mathrm{Si}$ and $\mathrm{Ni}_{3} \mathrm{P}$ ) crystalline phases. The corrected analysis (private communication, G. S. Cargill, III and D. E. Polk) indicates that about 13 at $\%$ of metalloid could be incorporated into the DRP structure in this way without serious deviations of the $A B$ 


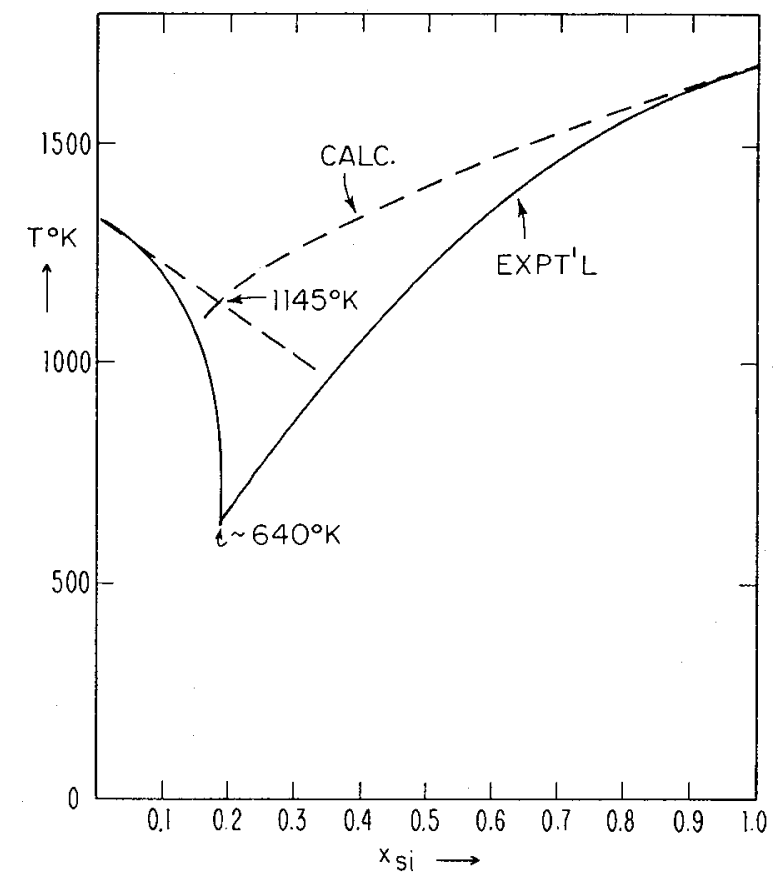

FIG. 3. - Comparison of experimental phase equilibrium diagram ( $p=1 \mathrm{~atm}$ ) of Au-Si system with diagram calculated assuming that liquid solutions behave ideally. Experimental diagram from M. Hansen, «Constitution of Binary Alloys》 (McGraw-Hill, N. Y.) 2nd ed. 1958 and first supplement (ed. by R. P. Elliott, 1965).

spacings from their values in the intermetallic phases and up to 20 at $\% \mathrm{~B}$ can be included with more severe distortions. Thus a «clathrate» like stabilization of the DRP structure may be effected when the preferred $\mathrm{AB}$ spacing, $R_{\mathrm{AB}}^{0}$, is compatible with the dimensions of the larger voids. Polk suggests that the higher concentrations of metalloid, $x_{B}>0.13$, in the amorphous structure may result either from a more loosely random packed structure which would be characterized by a higher proportion of the voids large enough to accommodate $\mathrm{B}$, or possibly by the substitution for A by B atoms on the DRP framework which would be formed entirely by $\mathrm{A}$ in the ideal structure. Sadoc et al. [39] conclude that Polk's model is oversimplified since their computer simulated packing of spheres of two different sizes indicate that the smaller spheres perturb the configurations of the larger spheres. However, Polk's model appears to be a valuable first order approach to viewing the SRO in these alloys.

Consider, in view of Polk's model, the structure of amorphous Ni-P which has been investigated quite thoroughly $[31,35,36]$. Although the volume contribution of the $\mathrm{P}$ atom in either the crystalline or amorphous structures of $\mathrm{Ni}_{3} \mathrm{P}$ to $\mathrm{Ni}$ is almost identical to that of the $\mathrm{Ni}$ atom, in crystalline $\mathrm{Ni}_{3} \mathrm{P}$ the smallest $\mathrm{Ni}-\mathrm{P}$ spacings, $R_{\mathrm{Ni}-\mathrm{P}}$, are less than the minimum $R_{\mathrm{Ni}-\mathrm{Ni}}$ by amounts as great as $11 \%$. This means that the Wigner-Seitz coordination number of $\mathbf{P}$ must be substantially less than that for Ni. According to Polk [17], P would be sited similarly in the larger voids of the DRP structure. Thus even though $P$ additions do not appreciably alter the average atomic volume in the amorphous alloy, we should expect to find that most of the nearest neighbor Ni-P separations are substantially less than those of $\mathrm{Ni}-\mathrm{Ni}$ and they should contribute a small shoulder at the front of the first peak in the RDF of Ni-P alloys. Polk noted some suggestion of such a shoulder in Cargill's RDF. Recently, Dixmier and Duwez [42] showed that the RDF of the similar $\left(\mathrm{Pd}_{50} \mathrm{Ni}_{50}\right)_{100-x} \mathrm{P}_{x}$ amorphous alloy can be interpreted satisfactorily when an apparent shoulder of this type is attributed to metal-phosphorus nearest-neighbor spacings which are about $20 \%$ smaller than those of the metal-metal.

The glass forming behavior of these systems seems consistent with a model in which the interatomic potentials $\Phi(R)$ would have the following features. When the potentials are scaled with their deepest minima corresponding, the repulsive branch of the A-A potential $\Phi_{\mathrm{AA}}(R)$ should climb more sharply with decreasing $R$ than does $\Phi_{\mathrm{AB}}(R)$. What form $\Phi_{\mathrm{BB}}(R)$ may have is less clear but it seems likely that its repulsive branch is considerably harder than that of $\Phi_{\mathrm{AB}}$. Further, the potentials for the glass formers should be of such magnitude that the energy of the system is lowered by A-B pairing. These potentials would define effective hard core diameters, $R_{\mathrm{A}}^{0}$ and $R_{\mathrm{B}}^{0}$ but owing to the softness of $\Phi_{\mathrm{AB}}(R)$ these diameters would be decreased in the alloy whenever $A$ and $B$ neighbor each other. Thus alloying of A with B would introduce, in the mean field context, an excess of «internal free volume» of mixing characterized by the dependence of $R_{\mathrm{A}}^{0}$ and $R_{\mathrm{B}}^{0}$ upon the composition and SRO in the alloy.

The microscopic basis for the model is that in pure metals of the A type the core-core interferences impose an interatomic separation considerably larger than that which would minimize the energy due to the interaction between the conduction electrons and positive ions. Thus when A interacts with atoms of the B type, which have Wigner-Seitz f. c. c. separations greatly exceeding the ion core sizes, there should be a strong tendency for the outer electrons of B to spread into the region occupied by the $\mathrm{A}$ core with the result that the preferred separation of $A$ and $B$ will be substantially smaller than one half the sum of the $A$ and B Wigner-Seitz f.c. c. separations. Heine and Weaire [34] have discussed this effect for the noble metals and note some experimental studies [43] indicating that the apparent atomic volume of the noble metals is indeed reduced somewhat when they are alloyed with certain B type elements.

The foregoing ${ }^{\varepsilon}$ model is in good accord with the thermal measurements which indicate that the local order in the molten alloys increases markedly with falling temperature. This ordering would result, as Polk suggested and as the structural studies indicate, 
in the formation of an amorphous solid with a very high degree of compositional SRO.

Also, the model may provide some basis for explaining some other rather puzzling features of the thermodynamic behavior of A-B type molten alloys.

\section{TABLE II}

Enthalpy and excess entropy of mixing of liquid metals. Except for Au(Si) the parameters are for dissolution of one gram atom of solute in the host at infinite dilution. Apart from the $\mathrm{Au}(\mathrm{Si})$ result, which was taken from the paper of Chen and Turnbull [29], all the results are taken from Kleppa's [44] summary.

\begin{tabular}{|c|c|c|c|c|c|}
\hline Host & Solute & $T^{\circ} \mathrm{C}$ & $\Delta \bar{H}^{\circ}\left(\frac{\mathrm{kcal}}{\mathrm{mole}}\right)$ & $\Delta \bar{S}_{x \mathrm{~s}}^{0}$ & $\left(\frac{\text { cal }}{\text { mole-deg. }}\right)$ \\
\hline 一 & - & - & - & & - \\
\hline \multirow[t]{4}{*}{$\mathrm{T} 1$} & $\mathrm{Cu}$ & 450 & 8.2 & & 2.0 \\
\hline & $\mathrm{Ag}$ & 450 & 3.6 & & 1.2 \\
\hline & $\mathrm{A}_{y}$ & | 300 & -0.5 & & - \\
\hline & $\mathrm{Ad}$ & 700 & 0.25 & & 2.4 \\
\hline \multirow{4}{*}{$\mathrm{Pb}$} & $\mathrm{Cu}$ & 450 & 6.7 & & 1.4 \\
\hline & $\mathrm{Ag}$ & 450 & 3.0 & & 1.0 \\
\hline & A & 300 & -2.4 & & 一 \\
\hline & $\mathrm{Au}$ & 600 & -1.0 & & 1.3 \\
\hline \multirow[t]{4}{*}{$\mathbf{B i}$} & $\mathrm{Cu}$ & 450 & 4.6 & & 1.4 \\
\hline & $\mathrm{Ag}$ & 350 & 2.9 & & 1.7 \\
\hline & $A_{1}$ & $\int 300$ & 0.25 & & - \\
\hline & $\mathrm{Ru}$ & 1700 & 1.0 & & - \\
\hline $\mathrm{Au}$ & $\mathrm{Si}$ & 1063 & $\sim-10$ & & 2.6 \\
\hline
\end{tabular}

In particular, (see Table II) the entropies of forming these alloys from their pure molten constituents often exceed the ideal entropy of formation, $\Delta \bar{S}_{\mathrm{Id}}=-R\left\{x_{\mathrm{A}} \ln x_{\mathrm{A}}+x_{\mathrm{B}} \ln x_{\mathrm{B}}\right\}$, by rather substantial amounts. These entropy excesses, $\Delta \bar{S}_{x \mathrm{~s}}$ even appear in systems where the heats of formation deviate substantially from $« 0 »$, either positively, as in $\mathrm{Tl}(\mathrm{Cu})$, or negatively, as in $\mathrm{Au}(\mathrm{Si})$. Kleppa [44] observed that, in some instances at least, the algebraic values of $\bar{\Delta} H^{0}$ and $\Delta \bar{S}_{x s}^{0}$ both fall with decreasing temperature. Kleppa's surmise that there would be no substantial volume increase in the mixing of these alloys seems borne out by the few measurements available. Indeed, Rossolimo and the author [45] found that the volume change in the mixing of molten $\mathrm{Pb}$ and $\mathrm{Au}$ (undercooled) at $618 \mathrm{~K}$ is negative, corresponding to a partial atomic volume of $\mathrm{Au}$ in lead rich alloys about $14 \%$ less than that of pure undercooled molten Au. Kleppa suggested that the large entropy excesses reflect unusually large amplitudes of the $\mathrm{A} \leftrightarrow \mathrm{B}$ oscillations which would imply that the $A B$ repulsive potential is, indeed, quite soft. As already indicated, in the mean field model (MFM) the effect of the weak A-B repulsion is increasing «internal free volume », reflected by the entropy excess, with alloying. Hildebrand [46] derives, using the MFM, the following simple expression for the entropy of mixing :

$$
\begin{aligned}
\Delta \bar{S}=R\left\{x_{\mathrm{A}} \ln \left(\frac{x_{\mathrm{A}} \eta_{\mathrm{A}}^{0}+x_{\mathrm{B}} \eta_{\mathrm{B}}^{0}}{x_{\mathrm{A}} \eta_{\mathrm{A}}^{0}}\right)+\right. \\
\left.+x_{\mathrm{B}} \ln \left(\frac{x_{\mathrm{A}} \eta_{\mathrm{A}}^{0}+x_{\mathrm{B}} \eta_{\mathrm{B}}^{0}}{x_{\mathrm{B}} \eta_{\mathrm{B}}^{0}}\right)\right\} .
\end{aligned}
$$

Here $x$ is the atom fraction and $\eta^{0}$ is the «free volume » of the designated component. In the simple model $\eta^{0}$ is taken to be $v^{0}-b^{0}$ where $v^{0}$ and $b^{0}$ are respectively the atomic and excluded volumes in the pure constituent; $b^{0}$ is determined by the effective hard core diameter, which is generally temperature dependent. While this simple method of applying the MFM does not account very well for the behavior of pure liquids, it has, as Prigogine [47] emphasized, been used with moderate success to calculate the differences between the properties of solutions and their pure constituents. In applying the model to A-B alloys we allow the effective hard core radii, hence $b$ and $\eta$, to vary with composition as well as with temperature. This leads to the following expression for the excess entropy :

$$
\begin{aligned}
\Delta \bar{S}_{x \mathrm{~s}}=R\left\{x_{\mathrm{A}} \ln \left(\frac{x_{\mathrm{A}} \eta_{\mathrm{A}}+x_{\mathrm{B}} \eta_{\mathrm{B}}}{\eta_{\mathrm{A}}^{0}}\right)+\right. \\
\left.\quad+x_{\mathrm{B}} \ln \left(\frac{x_{\mathrm{A}} \eta_{\mathrm{A}}+x_{\mathrm{B}} \eta_{\mathrm{B}}}{\eta_{\mathrm{B}}^{0}}\right)\right\} .
\end{aligned}
$$

A first order correction of the effect of composition on the $\eta$ 's results in :

$$
\begin{aligned}
\Delta \bar{S}_{x \mathrm{~s}}= & R\left\{x_{\mathrm{A}} \ln \left(\frac{x_{\mathrm{A}} \eta_{\mathrm{A}}^{0}+x_{\mathrm{B}} \eta_{\mathrm{B}}^{0}+a x_{\mathrm{A}} x_{\mathrm{B}}}{\eta_{\mathrm{A}}^{0}}\right)+\right. \\
& \left.+x_{\mathrm{B}} \ln \left(\frac{x_{\mathrm{A}} \eta_{\mathrm{A}}^{0}+x_{\mathrm{B}} \eta_{\mathrm{B}}^{0}+a x_{\mathrm{A}} x_{\mathrm{B}}}{\eta_{\mathrm{B}}^{0}}\right)\right\} .
\end{aligned}
$$

Figure 4 shows a fit of the composition dependence of the excess entropy of molten $\mathrm{Pb}-\mathrm{Au}$ alloys at $600^{\circ} \mathrm{C}$ to the simple Hildebrand expression, i. e.,

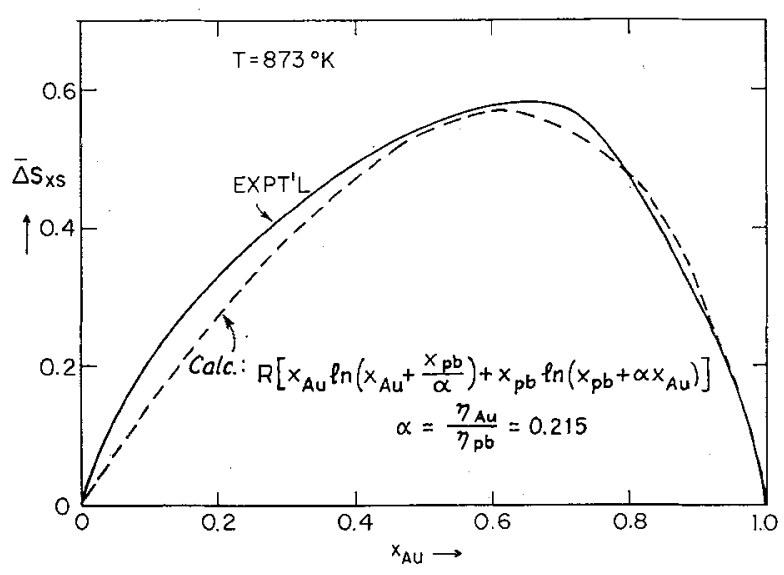

FIG. 4. - Comparison of measured excess entropy [42, 54] of molten $\mathrm{Pb}-\mathrm{Au}$ alloys with excess calcuiated from Hildebrand [44] expression (eq. 1). $\alpha$ chosen to make calculation match experimental value at $x_{\mathrm{Au}}=0.5$. 
(Eq. 3) with $a=0$. The fit was made with the ratio $\alpha=\eta_{\mathrm{Au}}^{0} \eta_{\mathrm{Pb}}^{0}$, taken as disposable and equal to 0.215 . It is grossly satisfactory, on the whole, but rather poor for the lead rich alloys. More importantly, the exceptionally low value required for $\alpha$ seems to imply an unreasonably large decrease, about $60 \%$ of the entropy of fusion, of the configurational entropy of molten $\mathrm{Au}$ upon cooling from $T_{\mathrm{m}}$ to $600^{\circ} \mathrm{C}$. Therefore, it seems that the excess entropy can be accounted for more plausibly by supposing, on the basis of our model, that $R_{\mathrm{Au}}^{0}$ and $R_{\mathrm{Pb}}^{0}$ are reduced markedly whenever $\mathrm{Pb}$ and $\mathrm{Au}$ neighbor each other (i. e., $a>0$ ) and Rossolimo [45] demonstrated this for the lead rich alloys by detailed calculations.

The algebraic decrease in both $\Delta \bar{S}_{x \mathrm{~s}}^{0}$ and the heat of formation with decreasing temperature presumably reflects an accompanying increase in SRO which reduces the compositional contribution to the configurational entropy.

The transition from melt to glass reflects a continuous solidification in which the shear viscosity is increasing rapidly with falling temperature over a narrow temperature interval. According to the MFM, or free volume model, this solidification results from increasing interparticle interferences which, at sufficiently small free volume, transform the interparticle motions from being translatory to primarily oscillatory in nature. The decrease in free volume with decreasing temperature, at constant pressure, results not only from the increasing particle density but also from the increasing effective hard core diameters of the particles. According to the model presented here, elements of the A type should exhibit relatively high glass temperatures because of the presumed hardness of the repulsive part of $\Phi_{\mathrm{AA}}(R)$. The addition of B to A ought actually to increase the internal free volume and thus the atomic transport coefficients, especially at high temperatures where the melt is completely disordered. There is some evidence of such effects. In particular, silicon additions reduce the viscosity of molten iron and Polk and the author [48] found that the viscosity of the molten glass-forming alloy $\mathrm{Au}_{0.78} \mathrm{Ge}_{0}{ }_{14} \mathrm{Si}_{0.08}$ at $406^{\circ} \mathrm{C}$ is less by a factor of 2 than the minimum plausible extrapolated value for the viscosity of pure molten gold.

If, indeed, the effect of B admixture is to lower the viscosity of molten A based alloys, then there should be a corresponding reduction in $T_{\mathrm{g}}$ of the fully disordered states of these alloys. However, the development of SRO might increase the glass temperature relative to that of the disordered state by one or the other, or both, of the following mechanisms. 1) As ordering occurs, $T_{\mathrm{g}}$ might be raised and even approach its value in pure $\mathrm{A}$ owing to the increasing proportion of A-A neighboring pairs; according to this view, $T_{\mathrm{g}}$ would correspond roughly to the temperature at which a certain high degree of SRO is developed. 2) As Chen [49] has suggested, the disordering energy may present a considerable barrier to the flow; in this event, $T_{\mathbf{g}}$ of the alloy might substantially exceed that of the pure A host. The second mechanism is supported by some measurements of Chen $[29,30,49]$ which show $T_{\mathrm{g}}$ increasing with increasing concentration of B. However, the B concentration ranges accessible to experiment were rather small. Also we note that the glass temperatures of $\mathrm{Au}_{4} \mathrm{Si}$ based alloys, $T_{\mathrm{g}} \sim 290 \mathrm{~K}$, are far less than that, $\sim 370 \mathrm{~K}$ for $\mathrm{Cu}_{50} \mathrm{Ag}_{50}$, as implied by Nowick and Maders' [26] results. Since $T_{\mathrm{g}}$ of pure Au ought, presumably, to be at least as high as that of $\mathrm{Cu}-\mathrm{Ag}$ alloy, these results suggest that $\mathrm{Si}$ additions to molten Au depress $T_{\mathbf{g}}$ and that the observed $T_{\mathrm{g}}$ may reflect the temperature of high SRO development.

According to either mechanism the flow resistance of the amorphous alloy should depend strongly on the SRO. This prediction is supported by the observations of Chen and the writer [29] that, following an abrupt temperature change, the shear viscosity of a $\mathrm{Au}_{4} \mathrm{Si}$ based alloy shifts from its initial to its final steady value over a much longer period than that in which the temperature change occurs. It follows that any spatial non-uniformity in the SRO would be reflected by non-uniformity of the flow resistance. Thus the plastic flow which occurs in some amorphous alloys well below $T_{\mathrm{g}}$ may be initiated in locally disordered regions and the striking localization of the deformation may result, as Polk and the author [48] suggested, from flow softening due to the concurrent disordering.

Certain alloys [31] composed by $\mathrm{A}$ and elements early in the transition series also have been melt quenched to amorphous solids; (e. g., $\mathrm{Cu}-\mathrm{Zr}$ [50] and $\left.\mathrm{Cu}^{-\mathrm{Ti}_{i}}[50]\right)$. While the early transition metals may be thought of as B type, these alloys are exceptional in that their amorphous structures can accommodate more than $50 \% \mathrm{~B}$ and at these compositions the glass temperatures are well above those indicated for certain of the A components. These alloy systems exhibit a number of stable intermetallic crystalline phases but the liquidus courses indicate that the liquid alloys are relatively very stable as well. Structural studies have revealed [51] that in the $\mathrm{Cu}-\mathrm{Ti}$ system, at least, the atomic volumes of the intermediate phases, from $\mathrm{Cu}_{3} \mathrm{Ti}$ through $\mathrm{CuTi}_{3}$, are from $8-13 \%$ less than the stoichiometric average of the atomic volumes of the constituents in their pure crystalline states. Thus $\mathrm{Cu}$ and $\mathrm{Ti}$, like the other AB glass formers, exhibit in their alloys minimum $A B$ separations well below the average of those of their pure states. Apparently, the B/A atomic volume ratios of most of these glasses are far above those of the other $\mathrm{AB}$ glasses considered here. These high ratios, as well as the relatively high melting temperatures of the pure B elements, may provide the basis for explaining the relatively high $T_{\mathrm{g}}$ 's of the alloys. Giessen and Wagner [31] have discussed alloying effects on glass formation in these systems more fully. 
2. Fast diffusion and interstitial solution behavior. - The phenomenology and understanding of fast diffusion in alloys have been reviewed by Anthony [52] and, more recently, by Warburton and the author [53]. Our interest in the present context is that alloys which exhibit fast diffusion seem to have a reciprocal host-impurity relation to alloys which are especially prone to amorphous solid formation; and this relation may reflect an essentially similar type of A-B interaction.

The hosts for fast diffusion identified so far have been $B$ type electropositive elements with large lattice parameters; in particular, $\mathrm{Pb}, \mathrm{Sn}, \mathrm{In}, \mathrm{Tl}$, alkali metals, $\mathrm{Zr}$ [54] and certain lanthanides and actinides. Impurities known to be fast diffusers include the noble metals, $\mathrm{Co}$ and $\mathrm{Ni}$, all of which are $\mathrm{A}$ type, and $\mathrm{Zn}$, $\mathrm{Cd}$ and $\mathrm{Hg}$, which exhibit an intermediate type of diffusivity in certain of the hosts.

Interpretation of the diffusivity behavior has led to the conclusion that the noble metals diffuse in $\mathrm{Pb}$, $\mathrm{Sn}$, In, and $\mathrm{Tl}$, and probably in the other B hosts as well; predominantly by interstitial mechanisms. It follows that the enthalpy differences, $\Delta H_{\mathrm{S} \text { i }}$, between the interstitial and substitutional states of the impurities can be no larger than the activation energies for diffusion, which range from about 4 to $15 \mathrm{kcal} / \mathrm{gm}$. atom $(0.2$ to $0.7 \mathrm{eV}$.). Thus the occupancy of interstitial sites by these impurities must be substantial; this result is very surprising since the Wigner-Seitz A/B radius ratios for all the systems are well above the Hagg empirical limit for predominantly interstitial solution. It has been noted that the largest interstices delineated by the positive ion cores of the $B$ structures are all large enough to accommodate the $\mathrm{A}$ atoms without core-core overlap. However, the minimum A-B spacings with A sited interstitially are far less than the preferred $\mathrm{AB}$ spacings in the liquid alloys [54A]. These results strongly support the concept that the repulsive part of the A-B interatomic potential is exceptionally soft.

Perhaps the most thoroughly studied fast diffusion is that of the noble metals in $\mathrm{Pb}$ hosts. For example, at infinite dilution $\mathrm{Au}$ diffuses, with an activation energy of $9400 \mathrm{kcal} / \mathrm{gm}$. atom, at rates, depending on $\mathrm{T}, 10^{4}$ to $10^{7}$ times those of $\mathrm{Pb}$. Turner et al. [55] discovered that strong internal friction peaks appear in $\mathrm{Pb}$ at low temperatures following the dissolution of small amounts of $\mathrm{Cu}, \mathrm{Ag}$, or Au. Analysis of the crystallographic dependence of the stress response indicated that the defect responsible for the internal friction has an off-center interstitial configuration which could result from an octahedrally sited interstitial atom pairing with a host atom through displacement along. a [100] direction. Warburton and the author [53] have coined the term « diplon » to designate this type of defect.

Turner et al. found that the activation enthalpies for reorientation of the A-B diplons are equivalent, within experimental error, to the corresponding activation enthalpies $\Delta H_{\mathrm{D}}$ in fast diffusion. It follows from these results that $\Delta H_{\mathrm{Si}}$ is either negative or negligible in comparison with $\Delta H_{\mathrm{D}}$ for all three of the impurities in $\mathbf{P b}$.

While the dissolution enthalpy $\Delta H_{\mathrm{Au}-\mathrm{Pb}}$ is slightly negative [44] for liquid $\mathrm{Au}$ in $\mathrm{Pb}$ it is about/ $+15 \mathrm{kcal} /$ gm. atom [57] for solid $\mathrm{Au}$ in the f. c. c. $\mathrm{Pb}$ host. This enthalpy change would include the enthalpy associated with decreasing the $\mathrm{Pb}-\mathrm{Au}$ separation below its preferred value and some enthalpy due to the accommodating distortion of the host. With no host relaxation the $\mathrm{Pb}-\mathrm{Au}$ separation in the interstitial defect would be about $2.5 \AA$, which is well below one half the sum, 3.2. $\AA$, of the Wigner-Seitz f.c. c. separations of the pure elements as well as the indicated minimum separation $\sim 3.05 \AA$ in the liquid alloy.

Internal friction [55] and precipitation kinetic studies [57] have shown that in a lead host there is an association which increases with increasing concentration $\chi_{\mathrm{A}}$, or falling temperature at given $\chi_{\mathrm{A}}$, of two $\mathrm{A}-\mathrm{B}$ diplons to an A-A diplon in which two $\mathrm{A}$ atoms are paired on one substitutional site.

$$
2 \mathrm{~A}-\mathrm{B}(\mathrm{d})+\mathrm{v} \rightarrow \mathrm{A}-\mathrm{A}(\mathrm{d})+2 \mathrm{~B}(\mathrm{~s})
$$

where $\mathrm{d}, \mathrm{v}$ and $\mathrm{s}$ denote, respectively, diplon, vacancy and substitutional. Provided the A-A diplons are relatively immobile, such association will lead to decreasing diffusivity of $A$ in B. Recently Warburton [58] has shown that the diffusivity of $\mathrm{Au}$ in $\mathrm{Pb}$ does drop quite sharply with increasing $\chi_{A}$ and that the effect is greater the lower is the temperature.

At equilibrium the interstitial concentrations of $\mathrm{A}$ in $B$ hosts are not known to exceed 0.1 to 0.2 at $\%$. However, Giessen et al. [59, 60] have succeeded in forming, by splat cooling, supersaturated solutions with very much higher contents of interstitial $A$. In particular, they demonstrated by X-ray and dilatometric density determination that up to 10 to 12 at \% of $\mathrm{Cu}$ or $\mathrm{Fe}$ can be retained in as interstitials, e. g., as A-B diplons in a Yttrium host [59]. In gadolinium hosts [60] similar amounts of $\mathrm{Cu}$ and $\mathrm{Fe}$ can be retained but primarily in the form of $\mathrm{A}-\mathrm{A}$ diplons.

Acknowledgment. - The author's research programs in the subject areas discussed in this paper have been supported, in part, by grants from the Office of Naval Research, National Science Foundation and Advanced Research Projects Agency. 


\section{References}

[1A] The interrelation between the microcrystallite and continuous random models was discussed by TuRNBUll $D$. and Polk, D. E., J. Non-Crystalline Solids 8-10 (1972) 19.

[1] Turnbull, D. and CeCh, R. E., J. Appl. Phys. 21 (1950) 804.

[2] Turnbull, D., J. Chem. Phys. 20 (1952) 411.

[3] Ovsienko, D. E., Maslov, V. V. and Kostyvchenko, V. P., Sov. Phys. Crystallogr. 16 (1971) 331.

[4] Bernal, J. D., a) Nature 185 (1960) 68; b) Proc. R. Soc. 280 A (1964) 299.

[5] Comen, M. H. and Turnuull, D., a) J. Chem. Phys. 31 (1959) 1164 ; b) ibid. 34 (1961) 120 ; c) ibid. 52 (1970) 3038.

[6] Cohen, M. H. and Turnbull, D., Nature 203 (1964) 964.

[7] Alder, B. J., Hoover, W. G. and Young, D. A., J. Chem. Phys. 49 (1968) 3688.

[8] Alder, B. J., Gass, D. M. and Wannwright, T. E., J. Chem. Phys. 53 (1970) 3813.

[9] BennetT, C. H., to be published.

[10] a) Bennetr, C. H., Ph. D. thesis in Chemical Physics, Harvard Univ., Cambridge, Máss. (Nov. 1970); $J$. Appl. Phys. 43 (1972) 2727; b) Norman, L. D. and Maust, E. E., Meeting Met. Soc. A. I. M. E. May (1970), Las Vegas, Nev.; c) Adams, D. J. and Matheson, A. J., J. Chem. Phys. 56 (1972) 1989.

[11] Dymond, J. H. and Alder, B. J., J. Chem. Phys. 45 (1966) 2061.

[12] Turnbull, D., «Solidification», pp. 1-22, Am. Soc. Metals, 1969 Seminar Volume, Metals Park, Ohio (1971).

[13] Ascarelli, P. and Paskin, A., Phys. Rev. 165 (1968) 222.

[14] Protopapas, P., Andersen, H. C. and Parlee, N. A. D., J. Chem. Phys. 59 (1973) 15.

[15] Frank, F. C., Proc. R. Soc. 215 A (1952) 43.

[16] BennetT, C. H., J. Appl. Phys. 43 (1972) 2727.

[17] Polk, D. E., a) Scripta Met. 4 (1970) 117; b) Acta Met. 20 (1972) 485.

[18] Alpress, J. G. and SAnders, J. W., Australian J. Physics 23 (1970) 23.

[19] Hoare, M. R. and Pal, P., a) Nature 230 (1971) 5 ; b) ibid. 236 (1972) 35 ; c) Adv. Phys. 20 (1971) 161.

[20] Weatre, D., Ashby, M. F., Logan, J. and Weins, M. J., Acta Met. 19 (1971) 779.

[21] Turnbull, D., J. Phys. Chem. 66 (1962) 609.

[22] Turnbull, D., Contemp. Phys. 10 (1969) 473.

[23] Bennett, M. R. and Wright, J. D., Phys. Stat. Sol. 13 A (1972) 135.

[24] Davies, H. A., Aucote J. and Hull, J. B., Submitted to Nature (1973).

[25] a) Hrssch, R. «Non-crystalline solids », ed. : R. D. Fréchette (Wiley, N. Y.) 1960 ; pp. 348-373, b) BückEL, W., Z. Phys. 138 (1954) 136.

[26] a) MADER, S., Widmer, H., D'Heurle, F. M. and Nowick, A. S., Appl. Phys. Lett. 3 (1963) 201 ; b) MADER, S. and Nowick, A. S., ibid. 7 (1965) 57; c) MADER, S., J. Vac. Sci. Tech. 2 (1965) 35.

[27] Nowick, A. S. and MAder, S., I. B. M. J. Res. and Dev. 9 (1965) 358.

[28] a) Klement, W., Willens, R. H. and Duwez, P., Nature 187 (1960) 869 ; b) Duwez, P., Trans. A. S. M. 60 (1967) 607 ; c) Duwez, P., Fizika 2 (1970) suppl. 2, pp. 1.1-1.5.

[29] Chen, H. S. and Turnbull, D., J. Chem. Phys. 48 (1968) 2560.
[30] ChEN, H. S. and Turnbull, D., Acta Met. 17 (1969) 1021. [30a] Bagley, B. G., Chen, H. S. and Turnbull, D., Mats. Res. Bulletin 3 (1968) 159.

[31] Gressen, B. C. and Wagner, C. N. J., «Physics and chemistry of liquid metals $»$, ed. : S. Z. Beer (Dekker) 1972, pp. 633-695.

[32] Polk, D. E., Bennett, C. H. and Turneuld, D., Acta Met. 19 (1971) 1295.

[33] MotT, N. F. and JoNEs, H., «Theory of the properties of metals and alloys », (Clarendon Press, Oxford) 1936, pp. 144-146.

[34] Heine, V. and Weaire, D., Solid state physics 24, 250-462 ed. : Ehrenreich, Seitz and Turnbull (Academic Press, N. Y.) 1970.

[35] Cargill, G. S. UII, J. Appl. Phys. 41 (1970) 12.

[36] Cargill, G. S. III, J. Appl. Phys. 41 (1970) 2248.

[37] Ashry, M. F., to be published.

[38] Polk, D. E., J. Non-Crystalline Solids 11 (1973) 381.

[39] SAdoc, J. F., Dixmier, J. and Guinier, A., J. Non-Crystalline Solids 12 (1973) 46.

[40] Cohen, M. H. and Turnbuld, D., Nature 189 (1961) 131.

[41] Finney, J. L., a) Ph. D. Thesis, University of London, U. K. (1968); b) Proc. R. Soc. (London) 319 A (1970) $479,495$.

[42] Dixmrer, J. and Duwez, P., J. Appl. Phys. 44 (1973) 1189.

[43] Nevitt, M. V., « Phase stability in metals and alloys», ed. : P. S. Rudman (McGraw-Hill, N. Y.) 1966, p. 281.

[44] KuEPPA, O. J., J. Phys. Chem. 60 (1956) 446.

[45] Rossolimo, A. N., Ph. D. Thesis, Harvard University, Cambridge, Mass. June 1971.

[46] Hildebrand, J. H., J. Chem. Phys. 15 (1947) 225.

[47] Prigogrne, I., «Molecular Theory of Solutions » (NorthHolland, Amsterdam) 1957.

[48] Polk, D. E. and Turnbull, D., Acta Met. 20 (1972) 493.

[49] Chen, H. S., J. Non-Crystalline Solids (in press).

[50] a) Ruhl, R., Gressen, B. C. and Grant, N. J., Acta Met. 15 (1967) 1693; b) Ray, R., Giessen, B. C. and Grant, N. J., Scripta Met. 2 (1968) 357 ; c) RevcolevschI, A. and Grant, N. J., Met. Trans. AIME 3 (1972) 1545.

[51] Pearson, W. B., «The crystal chemistry and physics of metals and alloys" (Wiley-Interscience, N. Y.) 1972.

[52] ANThony, T. R., "Vacancies and interstitials in metals 》, ed. : A. Seeger et al. (North Holland, Amsterdam) 1970.

[53] Warburton, W. K. and Turnbull, D., «Diffusion in solids : Recent developments $»$ ed. : A. S. Nowick and J. J. Burton (Academic Press, N. Y.) in press.

[54] Kidson, G. V., to be published.

[54A] a) Enderby, J. E., North, D. M. and Egelstaff, P. A., Phil. Mag. 14 (1966) 961 ; b) North, D. M., and WaGner, C. N. J., Phys. Chem. Liquids 2 (1970) 87.

[55] Turner, T. J., Painter S. and Nielsen, C. H., Solid State Commun. 11 (1972) 577.

[56] Hultgren, R., OrR, R. L., Andereon, P. D., and KELLEY, K. K., " Selected values of thermodynamic properties of metals and alloys "), (J. WILEY, N. Y.) 1963.

[57] Rossolimo, A. N. and Turnbull, D., Acta Met. 21 (1973) 21.

[58] Warburton, W. K., Scripta Met. 7 (1973) 105.

[59] Gressen, B. C., Ray, R. and Hahn, S., Phys. Rev. Lett. 26 (1971) 509.

[60] Ray, R., Segnin, M. and Giessen, B., Solid State Commun. 10 (1972) 163. 